\title{
Corps Ronds and Corps Grains-Warty Dyskeratoma
}

\author{
Anubha Bajaji* \\ Histopathologist in A.B. Diagnostics, India \\ Submission: June 7, 2019; Published: June 14, 2019 \\ "Corresponding author: Anubha Bajaji, Histopathologist in A.B. Diagnostics, New Delhi, India
}

Keywords: Isolated darier's disease; Warty dyskeratoma; Dykeratosis follicularis; Head; Neck; Benign skin disease; Squamous epithelial cells; Chemical carcinogens; Tobacco intake

Abbreviations: UV: Ultraviolet; PCR: Polymerase Chain Reaction; DNA: Deoxy-Ribo-Nucleic Acid; RNA: Ribo-Nucleic Acid; MWDS: Multiple Warty Dyskeratoma of the Scalp; HKN: Hair Follicle Specific Keratins

\section{Preface}

Graham and Helwig addressed warty dyskeratoma as "isolated Darier's disease" or "follicular dyskeratoma "in 1954. The nomenclature of warty dyskeratoma was adopted by Szymanski in 1957. "Isolated dykeratosis follicularis" or warty dyskeratoma cogitates an infrequent, cutaneous proliferative lesion commonly situated on the head or neck. Warty dyskeratoma is described as an exceptional, benign skin disease which demonstrates a characteristic solitary papule or nodule with an impacted centroidal crater or comedo [1,2].

\section{Disease Characteristics}

Warty dyskeratoma is exemplified by a benign, papulo-nodular lesion which typically demonstrates an endophytic pattern of proliferating squamous epithelial cells, particularly in conjunction with folliculo-sebaceous unit. Preponderant acantholytic foci are additionally enunciated. Frequently, a singular, warty, dyskeratotic papule or nodule with occasional centric crater is cogitated.

Warty dyskeratoma predominantly appears in the middle aged to elderly population. The disorder is of obscure aetiology. Ultraviolet (UV) light, autoimmune attributes, exposure to chemical carcinogens and tobacco intake can be incriminated in disease pathogenesis.

Viral (human papilloma virus) infection as discerned with a polymerase chain reaction (PCR) assay is absent. However, detection of viral deoxy-ribo-nucleic acid (DNA) and ribo-nucleic acid (RNA) within the cellular epithelium layering villous projections can be cogitated as an incriminating factor in the genesis of warty dykeratoma.

Chronic actinic deterioration is devoid of implication in the genesis of warty dyskeratoma as lesions can appear in regions unexposed to sunlight $[2,3]$.
An acquired genetic mutation of ATP2A2 gene is discerned along with an absence of SERCA2 gene. Lesions of warty dyskeratoma are engendered from hair follicles as is indicated by preponderance of warty dyskeratoma on hair bearing areas such as scalp. Head and neck are a frequent site of disease incrimination. Lesions do not recede spontaneously.

Warty dyskeratoma can appear on mucosal surfaces at sites devoid of hair follicles. However, inter-relation amidst mucosal and cutaneous lesions remains obscure.

Histology of warty dyskeratoma is identical to keratotic papules of Darier's disease and warty dyskeratoma can be contemplated as a variant of Darier's disease.

Individuals with multiple warty dyskeratoma usually lack a family history of adjunct conditions such as Darier's disease or acantholytic dermatosis as cogitated in Grover's disease. Multiple warty dyskeratoma can elucidate several or an enhancing quantification of asymptomatic papules on the scalp or forehead. Innumerable, flesh coloured or greyish, hyperkeratotic papules or nodules with a distinctive, umbilicated core can be delineated $[3,4]$.

Multiple warty dyskeratoma of the scalp depicts a female preponderance $(70 \%)$, a Male: Female ratio of $1: 1.8$, a mean age of appearance at 56 years with a disease extent varying from 29 years to 84 years. Lesions can enumerate from 3 to 240 .

Multiple warty dyskeratoma can display associated morbidities such as cardiac dysarrythmia, hypertension, renal failure and chronic liver disease. Multiple warty dyskeratoma of the scalp is a rare variant and requires a distinction from acquired papulo-nodular lesions in adults.

Multiple warty dyskeratoma of the scalp necessitates a cogent histology, although dermatoscopy can be efficacious in diagnosis $[3,5]$. 


\section{Clinical Elucidation}

Majority of the lesions are solitary in warty dyskeratoma. Characteristically flesh coloured or brown, verrucous papules, nodules and cysts are enunciated. Exceptionally, multiple. lesions can appear on the face, scalp or dorsum. Adjunctive sites are implicated such as the cheeks, hands and chest.

Frequently manifested is a distinctive, discrete, cup shaped papule or nodule situated on the head and neck or trunk and extremities. Warty dyskeratoma can appear on mons pubis, subungual region, oral and genital mucosa $[4,5]$. Lesions vary from 1 millimetre to 12 millimetre in magnitude. The disorder is essentially asymptomatic; however, pruritus can occur accompanied by a relapsing, offensive, cheesy effluvium from the lesions. Centric haemorrhage can emerge in traumatic lesions. A centric zone akin to an umbilicus or a pore with a centroidal keratin plug can be cogitated. Multitudinous lesions of warty dyskeratoma are infrequent. Rare, multiple lesions appearing on the scalp are exemplified as "multiple warty dyskeratoma of the scalp" (MWDS). The variant was initially discerned in 1993. Multiple warty dyskeratoma of the scalp depicts an equivocal gender distribution with a Male to Female ratio of 1:1. As denominated, lesions are discerned on the scalp, face, neck, hand or torso. Scalp is a frequent site (75\%) followed by face (50\%). Asymptomatic scalp lesions are gradually progressive and demonstrate brownish papulo-nodular outgrowths which are minimally pruritic, measure 0.2 centimetres to 2.0 centimetres, evolve gradually and are discerned within months or years. Nodules can be erythematous with a yellowish, hyperkeratotic occlusion. Brownish or black verrucous lesions can be discretely disseminated or clustered $[5,6]$.

\section{Histological Elucidation}

Warty dyskeratoma is represented by cup shaped invaginations of the epidermis displaying epithelial hyperplasia and is accompanied by supra-basal acantholysis and dyskeratosis. The morphological characteristics are akin to Darier's disease. Typical lesions of warty dyskeratoma depict a well-defined, endophytic pattern of evolution with the appearance of corps ronds and corps grains. Additionally, a superficial covering of parakeratotic tissue is delineated. Dyskeratosis is predominantly and characteristically acantholytic. Aberrant linkage and keratinisation of squamous epithelial cells are cogitated. Inverted epidermal invaginations are congested with keratinous debris. Prominent clefts upon supra-basal epithelium are situated inferiorly on epidermal invaginations and configure ascending villous projections. Keratinous deposits are abundant and articulate keratin plugs with centric cellular proliferation [6,7].

Innumerable villous extensions upon the inferior segment of cup shaped depression are coated with a singular layer of basaloid epithelial cells. Invaginations can appear within an intensely distended hair follicle. A singular lesion can implicate two to four adjoining hair follicles. Admixture of histological features can be enunciated. Dyskeratotic keratinocytes appear within the stratum spinosum and stratum granulosum with the elucidation of corps ronds and corps grains, respectively. An accompanying thickened granular layer is demonstrated. Corps ronds and corps grains can project through the papillary dermis. Centric crater is distended with necrotic, cornified tissue. Sequential to the frequently elucidated cup shaped invaginations, cystic and nodular configurations are additionally cogitated.

Cystic category depicts enlarged; well demarcated cystic articulations confined to the dermis. Cystic arrangements are layered with epithelial cells and impacted with abundant keratinous substance. Nodular variant demonstrates miniature, well defined, circumscribed, solid aggregates of epithelial cells within the dermis. Epithelial accumulates are in continuation with superficial epidermis which enunciates epidermal hyperplasia [7,8]. Minimal to moderate inflammatory infiltrate comprising of lymphocytes and histiocytes can accrue in the superficial dermis underlying the tumefaction. Focal emergence of acantholytic dyskeratosis cannot be ascertained as a categorical morphological parameter of warty dyskeratoma.

Focal acantholytic dyskeratosis is additionally discerned in Darier's disease, transient acantholytic dermatosis, acantholytic squamous cell carcinoma, actinic keratosis and basal cell carcinoma. Multiple warty dyskeratoma of the scalp on histology depict a distinct, predominantly endophytic epidermal proliferation constituting a centroidal crater with impacted keratinous substance composed of dyskeratotic keratinocytes which additionally configure the classic corps ronds and grains. Inferior aspect of the principally epidermal lesion exhibits acanthosis, prominent papillomatosis and accumulation of dyskeratotic keratinocytes which appear submerged in acantholytic, supra-basal epithelial perforations. Epidermal extensions simulating a "villous" arise within epidermal clefts. Typical histology, abutting hair follicles and representative immune histochemical reactivity to hair follicle specific keratins (HKN) 5/17, particularly HKN-6 and HKN-7 is diagnostic. Thus, an alternative terminology of "follicular dyskeratosis" can be cogitated for multiple warty dyskeratoma of the scalp [8,9].

\section{Dermatoscopic Features}

Dermoscopic manifestations of warty dyskeratoma include whitish, homogenous zones demonstrating yellow clods interspersed with mature, distinct hair follicles. Additionally, pale to gray zones with a centric depression can be elucidated on dermatoscopy $[3,4]$.

\section{Differential Diagnosis}

Differentiation is necessitated from clinical conditions such as verruca, seborrheic keratosis, sebaceous cyst, sebaceous hyperplasia and hypertrophic actinic keratosis. Histological demarcation is a pre-requisite from conditions demonstrating acantholytic dyskerartosis on morphology such as acantholytic or dyskeratotic acanthoma, Darier's disease, Grover's disease, Hailey- Hailey disease, familial dykeratotic comedones, acantholytic actinic keratosis and acantholytic squamous cell carcinoma. 


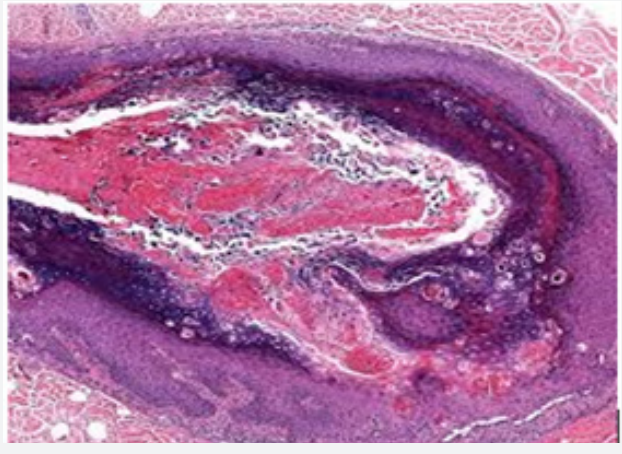

Figure 1: Cup shaped invaginations, acantholysis and dyskeratosis in warty dyskeratoma.

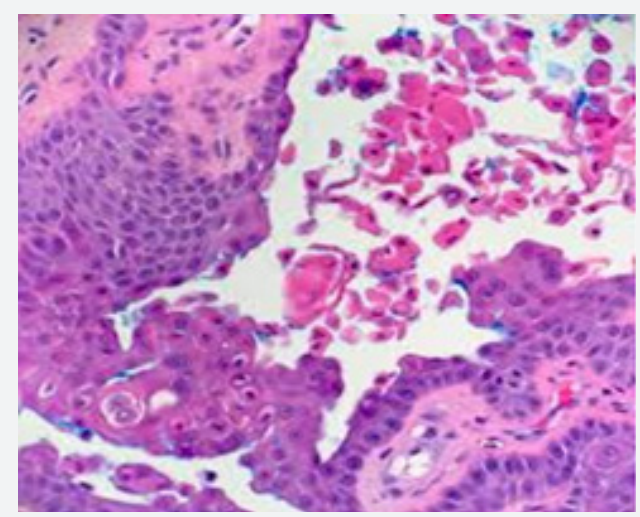

Figure 2: Cup shape configuration with corps ronds and acantholysis in warty dyskeratoma .

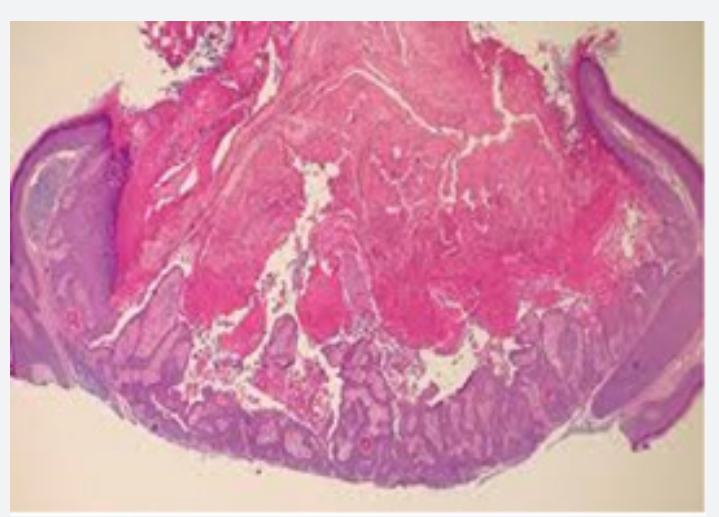

Figure 3: Crater with impacted keratinous material, villous projections and supra-basal clefts in warty dyskeratoma.

Appearance of definitive clinical aspects and emergence of villous epidermal hyperplasia at inferior segment of warty dyskeratoma assists in segregation from identical morphologies [9-11]. Warty dyskeratoma can be differentiated from Darier's disease and transient acantholytic dermatosis on the basis of specific clinical attributes. As the lesions are devoid of cellular atypia and display particular morphological features, conditions such as squamous cell carcinoma, actinic keratosis or basal cell carcinoma can be excluded. Differentiation on histological grounds is necessitated from conditions such as i) Benign familial pemphi- gus or Hailey-Hailey disease which displays excessive acantholysis within enlarged zones of epidermis. ii) Darier's disease which requires clinic-pathological concordance for appropriate diagnosis. iii) Pemphigus vegetans which demonstrates enhanced foci of acantholysis. Eosinophilic aggregates are cogitated within the epidermis. Surgical specimens submitted for immune fluorescence can be utilized for discerning pemphigus vegetans $[3,4]$ [Figures 1-12].

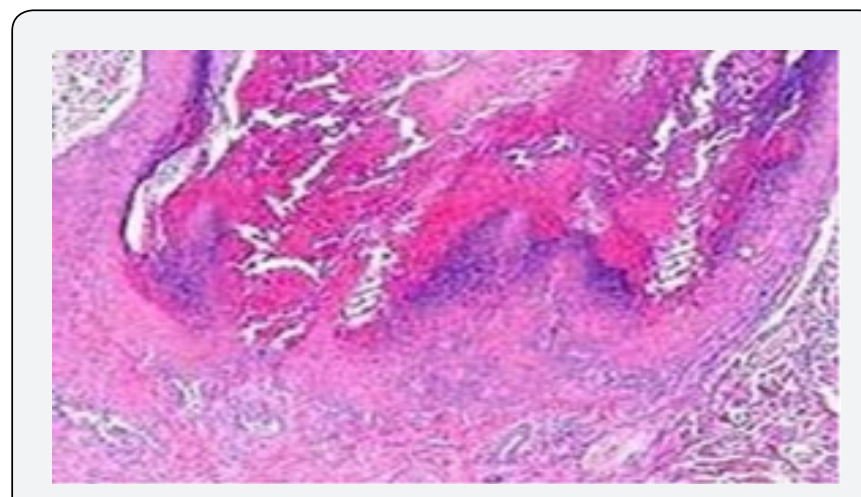

Figure 4: Acantholysis, dyskeratosis, villous extension and crateriform articulation in warty dyskeratosis

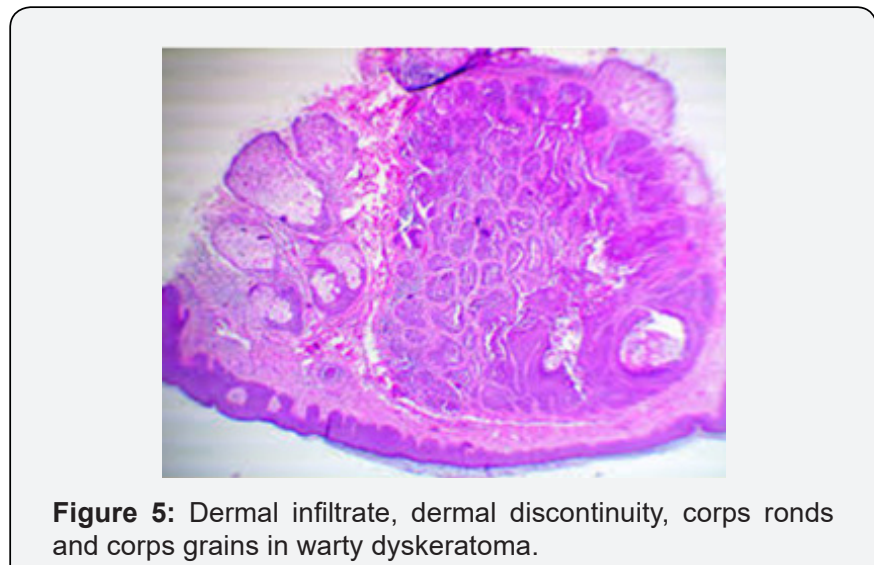

and corps grains in warty dyskeratoma.

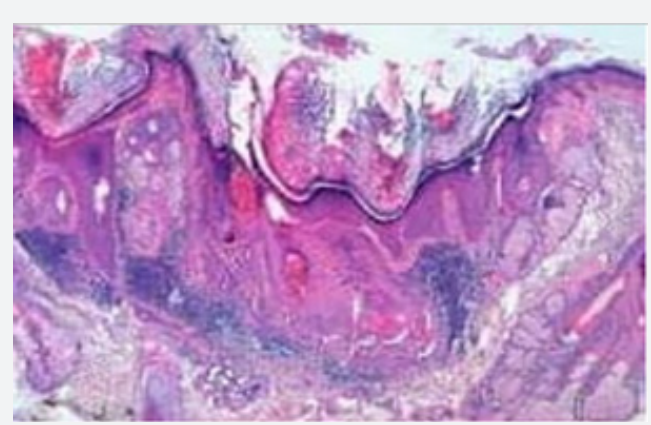

Figure 6: Warty dyskeratoma with supra-basal epithelial perforation, epidermal villous extensions and acantholytic dyskeratosis .

\section{Therapeutic Regimens}

Optimal treatment comprises of surgical extermination of the lesions, although it is not a pre-requisite with benign histology. Surgical eradication is a cogent form of therapy. Partial or incompletely elucidated lesions can be suitably surgically eliminated. 
Apart from surgical excision, curettage, electrodessication and irradiation with $\mathrm{X}$ rays can be employed to remove the lesions. However, lesions can reoccur with the utilization of aforesaid treatment modalities.

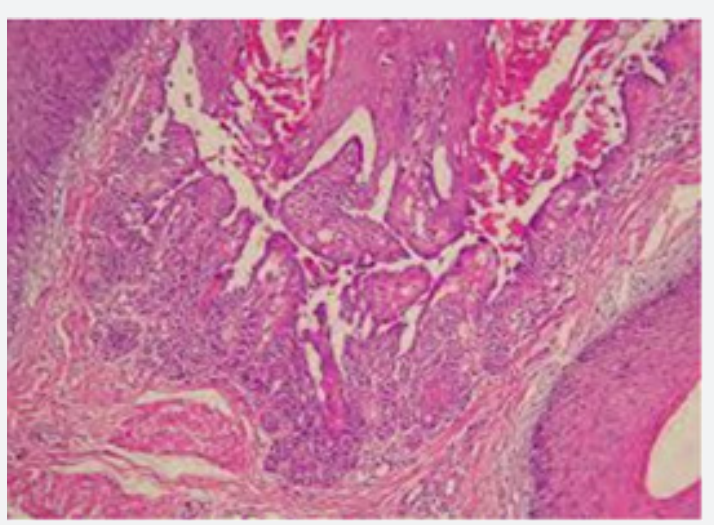

Figure 7: Supra-basal clefts, villous elongation, corps ronds and minimal inflammation in warty dyskeratoma.

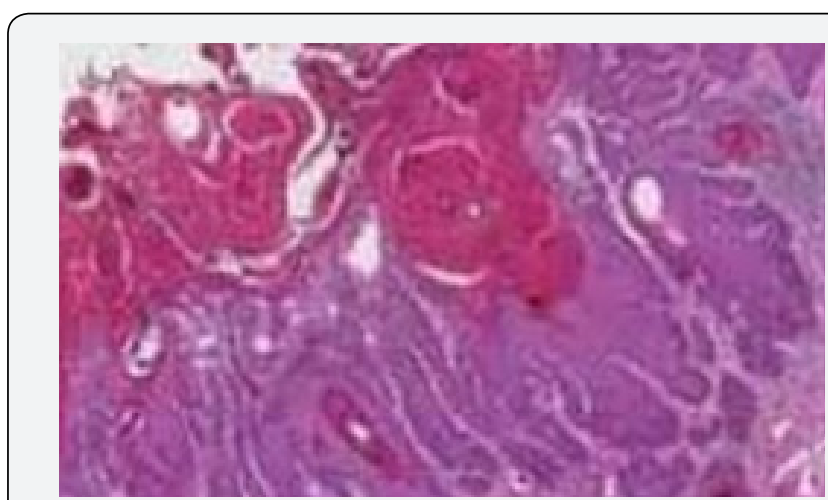

Figure 8: Cup shaped invaginations, acantholysis, dyskeratosis and epithelial aggregates in warty dyskeratosis.

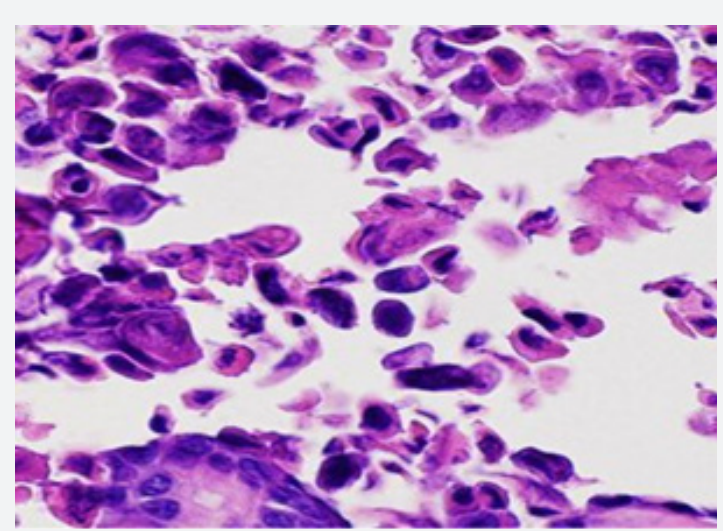

Figure 9: Acantholytic dyskeratosis in a cavitary depression of warty dyskeratosis.

Administration of tazarotenic acid gel is beneficial. Systemic administration of isotretinoin in combination with topical tretinoin application can achieve significant alleviation. Reoccurrence of the lesions is exceptional. Malignant transformation does not ensue $[9,11]$.

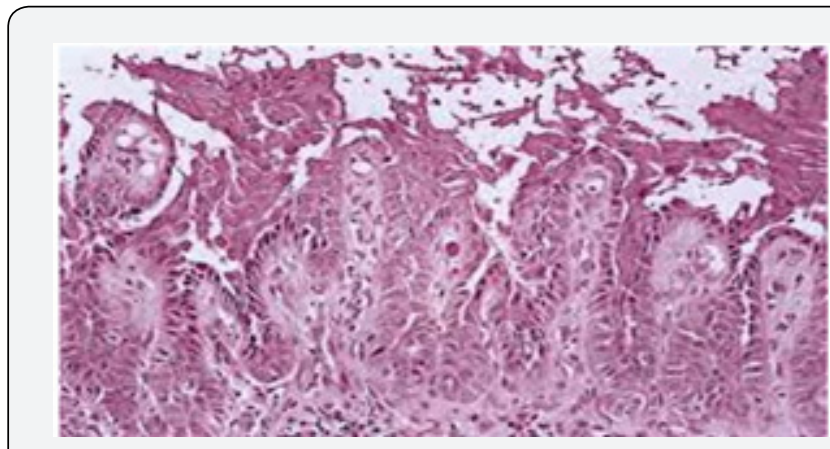

Figure 10: Ascending villous projections, supra-basal cellular dehiscence, thickened granular layer and acantholysis in warty dyskeratosis.

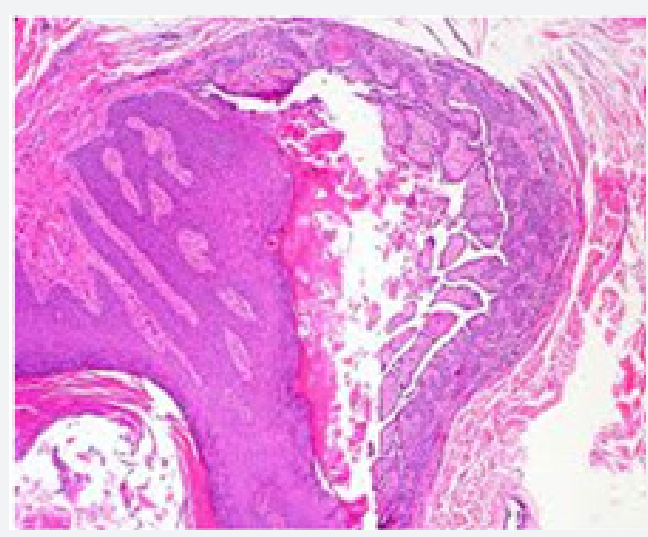

Figure 11: Luminal villous aggregates, acantholysis, keratinous debris and cup shaped cellular arrangement in warty dyskeratosis.

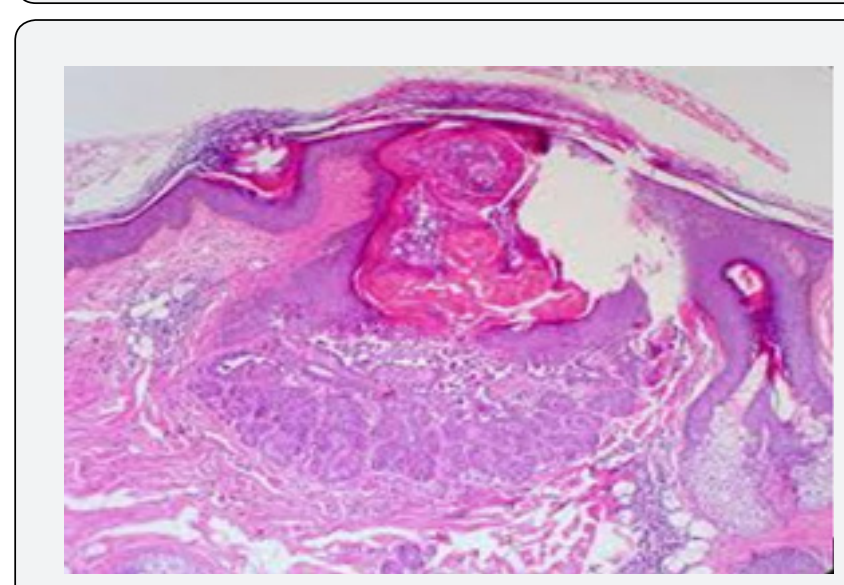

Figure 12: Mild dermal inflammation, corps ronds, corps grains, supra-basal clefts and epidermal continuity in warty dyskeratoma.

\section{References}

1. Szymanski FJ (1957) Warty dyskeratoma: A benign cutaneous tumor resembling Darier's disease microscopically. AMA Arch Derm 75(4): 567-572.

2. Graham JH, Helwig EB (1958) Isolated dyskeratosis follicularis. AMA Arch Derm 77(4): 377-389.

3. Alomran H, Asvesti K, Tsega A, Kanitakis J (2018) Multiple warty dyskeratoma of the scalp: report of a new case and review of literature. Eur J Dermatol 28(4): 555-556. 
4. Jang EJ, Lee JY (2011) Warty dyskeratoma involving two adjoining follicles. Ann Dermatol 23(1): 98-100.

5. Wang S, Bai J (2018) Multiple warty dyskeratoma: case report and review of literature. Int J Clin Exp Med 11(5): 5241-5244.

6. Salerni G, Alonso C (2017) Dermoscopy of multiple warty dyskeratoma. Dermatol Pract Concept 7(4): 47-49.

7. Koc M, Kavala M (2009) Multiple warty dyskeratomas on the scalp. Dermatol Online J 15(2): 8.

8. Ugras M, Adim SB, Kilicoglu M, Baskan EB (2014) Multiple warty dyskeratomas: case report. Iran J Public Health 43(8): 1145-1147.
9. Kuo YL, Wu YH, Ying-Jui Chang (2011) Systemic isotretinoin with topical tretinoin cream in the multiple warty dyskeratoma. Dermatologica Sinica 29: 106-108.

10. Vargas-Laguna E, Imbernon-Moya A, Aguilar-Martínez A, Burgos F (2017) An unusual location of subungual warty dyskeratoma: a case report and review of literature. Case Rep Dermatol Med 2017: 3613109.

11. Lora V, Scarabello A, Cota C (2015) Warty dyskeratoma as a cutaneous horn of the mons pubis. Am J Dermatopathol 37(10): 802-804.

\section{Your next submission with JuniperPublishers will reach you the below assets}

- Quality Editorial service

- Swift Peer Review

- Reprints availability

- E-prints Service

- Manuscript Podcast for convenient understanding

- Global attainment for your research

- Manuscript accessibility in different formats

( Pdf, E-pub, Full Text, audio)

- Unceasing customer service

Track the below URL for one-step submission https://juniperpublishers.com/online-submission.php 